\title{
Severe thunderstorm and tornado warnings in Europe
}

\author{
Jenni Rauhala ${ }^{\mathrm{a}, *}$, David M. Schultz ${ }^{\mathrm{b}, \mathrm{a}}$ \\ a Finnish Meteorological Institute, Helsinki, Finland \\ ${ }^{\mathrm{b}}$ Division of Atmospheric Sciences and Geophysics, Department of Physics, University of Helsinki, Helsinki, Finland
}

\section{A R T I C L E I N F O}

\section{Article history:}

Received 7 December 2007

Received in revised form 29 August 2008

Accepted 20 September 2008

\section{Keywords:}

Severe thunderstorm warnings

Tornado warnings

Convective storms

Forecasting

Verification

\begin{abstract}
A B S T R A C T
This study summarizes the current severe thunderstorm warning and forecast operations in different European National Hydro-Meteorological Services (NHMSs), and, in doing so, suggests ways for countries developing their own warning service to learn from experiences in other countries, as well as from the warning operations in the United States of America, the longest-lived severe thunderstorm warning operations in the world. This study is based on a questionnaire sent to 39 European NHMSs of which thirty-three (85\%) responded. Currently, many European NHMSs are actively developing their severe thunderstorm forecast process and warning services with 26 (79\%) of respondent countries issuing severe thunderstorm warnings and $8(24 \%)$ issuing tornado warnings. Both warning criteria and methodologies used in the warning process vary from country to country. Lead-times range from $30 \mathrm{~min}$ to $96 \mathrm{~h}$, indicating a range of different warning philosophies for each country. Major challenges toward improving the warning operations include obtaining observations of severe weather for real-time forecasting and post-event verification, educating forecasters, and having access to state-ofthe-art forecaster workstations. An additional challenge is in communicating anticipated or ongoing severe thunderstorms, both internationally between NHMSs and nationally with media and emergency authorities.
\end{abstract}

(c) 2008 Elsevier B.V. All rights reserved.

\section{Introduction}

Severe thunderstorms have been observed in every country in Europe. In recent years, the increase in the number of documented severe thunderstorms in Europe (e.g., Brooks and Doswell, 2001) has improved awareness of that threat. Previously, the National Hydro-Meteorological Services (NHMSs) of many European countries had failed to even admit publicly the threat from tornadoes, let alone keep accurate records of severe weather occurrences. (This situation resembled the time before the 1950s in the United States of America (USA), as discussed by Galway (1989), Bradford (1999), and Doswell (2001, p. 14).) As Doswell (2001, pp. 14 and 181) has argued, the probability of severe weather reports being collected is proportional to the awareness of the threat

\footnotetext{
* Corresponding author. Finnish Meteorological Institute, Erik Palménin Aukio 1, P.O. Box 503, FI-00101, Helsinki, Finland. Tel.: +358 91929 3497; fax: +358 919294103 .

E-mail address: Jenni.Rauhala@fmi.fi (J. Rauhala).
}

and the efforts to mitigate the threat. Thus, the situation in Europe became what Doswell (2003,148-149) has referred to as a self-fulfilling prophecy: no recognition of the threat led to no record keeping of events and no acknowledgement of the threat even when observations were reported.

Thus, the risk that severe thunderstorms pose to society depends not only on the climatological probability of the event to occur, but also on how well society is prepared to handle the event once it occurs. The impacts of severe thunderstorms and tornadoes on society can be mitigated by developing warning processes within each country. Lessening the impact has aroused demand for warning programmes and, therefore, severe thunderstorm warning operations are currently being developed in many European countries. These warning programmes tend to be located within the NHMSs, as they are the logically responsible agency and "single authoritative voice" for providing forecasts and information on natural hazards "to save lives, to sustain productivity, and to reduce damage to property" (quotations from the EC statement on the role and operation of National Meteorological and Hydrological Services. (EC-LVII, 
ANNEX VII) http://ftp.wmo.int/pages/governance/policy/ ec_statement_nmhs_en.html).

Setting up a warning system for severe thunderstorms and tornadoes is complicated. Their forecasting and nowcasting require special knowledge and tools because their precise occurrence cannot be unambiguously anticipated from Numerical Weather Prediction (NWP) model fields and their small spatial extents elude detection by most operational observations. A special challenge lies in communicating the nowcasts and warnings to the emergency-management authorities, media, and public within the relatively short time scales upon which severe weather occurs.

Because of the large threat from severe weather faced by much of the USA, the forecasting, warning, and dissemination system in the USA is one of the most advanced in the world. As discussed by Doswell (2003, 2005), this system was developed mostly ad hoc rather than through a rigorous planning, implementation, and evaluation process. As such, pieces of the system exist that might have arisen differently had such a rigorous process been in place. Throughout this paper, we compare and contrast the European experience with that in the USA, looking for places where cross-cultural learning opportunities are possible.

In the present paper, severe weather is defined as damaging wind gusts, large hail, or a tornado, similar to the definition employed in the USA, where severe weather is defined as convectively induced phenomena that includes tornadoes, damaging winds or gusts $\geq 26 \mathrm{~m} / \mathrm{s}$ ( $50 \mathrm{kt}$ ) or hail diameter $\geq 1.9 \mathrm{~cm}$ (3/4 in.) (e.g., Johns and Doswell, 1992). Specific quantitative criteria for the wind speed and size of the hail vary by country and are discussed later in the paper. Waterspouts are here considered severe weather, unlike in the USA. Heavy rain and lightning/thunder are not generally included in the definition of severe weather, although these processes commonly occur in association with severe weather-producing storms.

The present study is largely based on a questionnaire sent to 39 European NHMSs. The purpose of this paper is threefold: (a) report on the results of that questionnaire, thus obtaining a general overview of severe thunderstorm and tornado forecasting and warning operations in Europe, (b) provide other NHMSs new ideas (from practices in other countries) on how to develop their severe thunderstorm warnings and warning process, and (c) identify areas that need improvement in Europe, possibly through international co-operation.

Section 2 of this paper reviews the severe thunderstorm warning system in the USA. Section 3 discusses the questionnaire and its dissemination. The results from the questionnaire addressing European severe thunderstorm and tornado warnings operations are presented in Sections 4 and 5 , respectively. Communication issues related to the questionnaire results are discussed in Section 6. Section 7 discusses the challenges faced by European NMHSs and provides suggestions for improvement. Finally, Section 8 concludes this paper.

\section{The warning process in the USA}

The modern forecasting and warning process for severe weather in the USA occurs in three steps (outlook, watch, and warning), products issued primarily by two different organi- zations within the NOAA National Weather Service (NWS) (e.g., Johns and Doswell, 1992; McNulty, 1995; Moller, 2001). (Tornado forecasts and warnings in the USA before World War II are described by Bradford (1999).) One to several days in advance of the forecasted severe weather, an outlook may be issued by the NWS Storm Prediction Center (SPC). The SPC provides forecasts of severe weather for the 48 continental United States (excluding Alaska and Hawaii). The history of the SPC is described in Galway (1989), Ostby (1992, 1999), Corfidi (1999) and Doswell (2007). In producing an outlook, forecasters primarily use guidance from numerical weather prediction models, looking for evidence of environments favourable for severe weather. In the second step, if severe weather is threatening to develop within 1-6 h, the SPC may issue a severe thunderstorm watch or tornado watch, if the threat includes a specific potential for tornadoes. The watch is issued by county, for an area loosely corresponding to a rectangular-shaped box, covering an average of $80,400 \mathrm{~km}^{2}$ (in 2006) where severe weather is expected. The third step is the warning. If individual storms have formed, or are about to form, and have a strong possibility of producing severe weather within the next 30-60 min or tornadoes within the next 15-45 min, an individual NWS Forecast Office (NWSFO) may issue a severe thunderstorm warning or a tornado warning, respectively, for a specific county (or portion of a county). Because the USA has 122 NWSFOs, the area of responsibility is much smaller than that of the SPC, allowing more specific warnings and careful localized attention to the severe weather, as well as a closer working relationship with the local emergency-management authorities, media, and public. An example of how NWSFOs make warning decisions is described in Hoium et al. (1997).

A specific example of how this forecasting process worked during the most damaging tornado outbreak in USA history (the Oklahoma-Kansas tornado outbreak of 3 May 1999, where over 60 tornadoes inflicted over a billion dollars in damage and 46 deaths) is described from two perspectives. The experiences of the SPC and Norman, Oklahoma, NWSFO are described in Edwards et al. (2002) and Andra et al. (2002), respectively.

\section{The questionnaire and methodology}

This study is based on a questionnaire sent to all European NHMSs in October 2006-November 2007. The questionnaire was sent by email and in person to selected persons who are experts on weather warning operations at each NHMS (Appendix A). Additional questions were asked of these persons if clarifications were needed to their initial answers. The questionnaire addressed severe thunderstorm and tornado warning operations, warning criteria and methods, and challenges faced by individual NHMSs in developing their warning operations. A large portion of the questionnaire considered the severe thunderstorm warning process (e.g., NHMS co-operation with media, emergency-management authorities, and neighbouring countries; dissemination of warnings; use of ground-truth reports). The questionnaire considered only warnings on severe thunderstorms and tornadoes; ordinary thunderstorms or other warning operations were not considered in this questionnaire. Severe thunderstorms were defined in the questionnaire as convective 
storms with damaging wind gusts or large hail or a tornado. Altogether, 39 European countries were surveyed, and 33 (85\%) responded. Appendix A provides the number of respondents for each question.

As discussed in Section 2, the USA has developed a threestep system for forecasting severe weather (outlook, watch, and warning). Such a three-step system and accompanying terminology is not employed in any European country. Thus, in the present paper, we apply the general term warning for any forecast of severe weather, regardless of lead-time or forecast methodology. Wherever possible in this paper, we hope to distinguish the forecasting process (the equivalent of the outlook process in the USA) from the nowcasting process (the equivalent of watches and warnings in the USA).

\section{Severe thunderstorm warnings in Europe}

European NHMSs forecast severe thunderstorms, thunderstorms with damaging wind gusts, large hail, or tornadoes before the storms have developed in 28 (85\%) of the 33 respondent countries. These forecasts are used to issue early warnings in 23 (70\%) of the respondent European NHMSs. In a few (5, or $18 \%$ ) countries, even if the event is forecasted, no warning is issued or the warnings are issued only after the storms have developed. Twenty-six (79\%) of respondent countries issue warnings for severe thunderstorms, damaging wind gusts, or large hail (Fig. 1). Most of the remaining 7 countries, however, issue general thunderstorm warnings for potential lightning danger.

The severe thunderstorm forecast and warning lead-time, defined from its issuance to the first severe weather report, has quite a bit of variability between the respondent countries. Of the 28 countries that forecast severe thunderstorms, 8 (29\%) may issue their forecasts more than $24 \mathrm{~h}$ before the event, with one country issuing forecasts $96 \mathrm{~h}$ in advance. However, the most common severe thunderstorm forecast lead-time is $24 \mathrm{~h}$ (11 respondents, or 39\%).

In contrast to forecasts, the typical lead-time for warnings varies from 30 min to $96 \mathrm{~h}$, indicating that different warning philosophies are used among the different countries. Interestingly, 6 (23\%) of the 26 respondents that issue warnings do so $24 \mathrm{~h}$ before the event. Such is the system, for example, in Finland, where a severe thunderstorm warning may be issued for anticipated severe weather $24 \mathrm{~h}$ in advance over a large area for a general time frame (analogous to the outlook process in the USA) or for observed severe weather in real time where the risk is more limited spatially and temporally (analogous to the watch or warning process in the USA). By

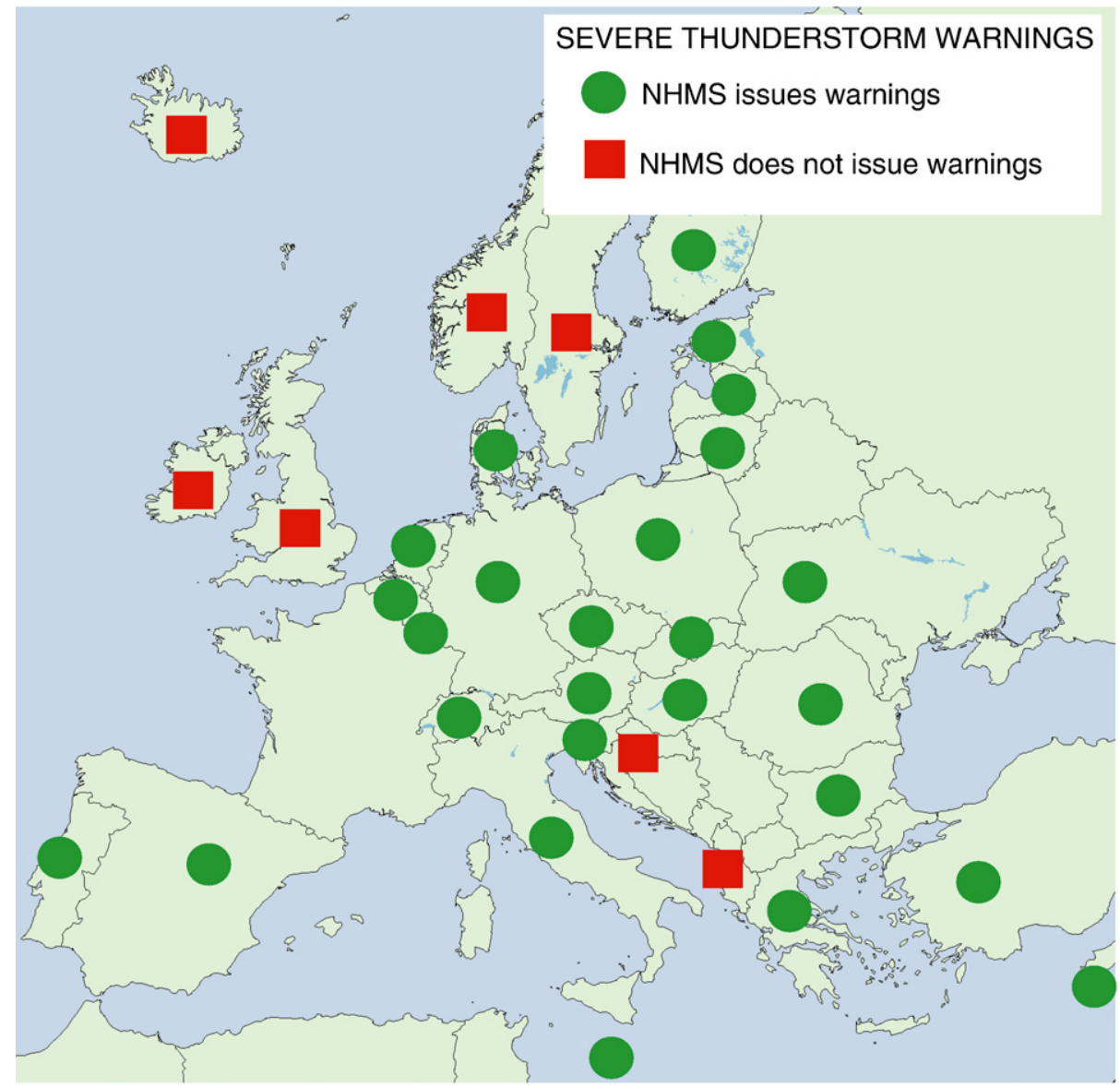

Fig. 1. Severe thunderstorm warnings for damaging wind gusts or large hail in Europe. Countries that issue severe thunderstorm warnings are denoted with a circle, the ones that don't with a square. 
comparison, most countries (16, or $62 \%$ ) issue warnings with $6 \mathrm{~h}$ or less lead-time, 11 (42\%) issue warnings with $3 \mathrm{~h}$ or less lead-time, and 2 ( $8 \%$ ) issue warnings with a typical lead-time of $30 \mathrm{~min}$. By comparison, the average lead-time for severe thunderstorm watches in the USA is $57 \mathrm{~min}$ (in 2006) and for severe thunderstorm warnings in the USA is $17 \mathrm{~min}$ (in 2007).

The warning criteria, if specified by the respondents, varies considerably among the countries (Table 1 ). In addition to the 23 countries listed in Table 1, Belgium, Denmark, and Luxembourg issue severe thunderstorm warnings, but their criteria does not depend on the expected gust speed or hail size. Furthermore, many countries have two or three awareness levels for their thunderstorm warnings depending upon the forecasted severity (e.g., Cyprus, Hungary, and Lithuania in Table 1).

The minimum expected wind gust speed is used as a criterion in 23 countries ( $88 \%$ of the 26 countries that issue severe thunderstorm warnings) (Table 1). Eleven (48\%) of the countries that use the wind gust speed as a criterion have more than one awareness level for these warnings. The minimum wind speed criterion for thunderstorm gust warnings may be as low as $11 \mathrm{~m} / \mathrm{s}$ or as high as $28 \mathrm{~m} / \mathrm{s}$. By comparison, the minimum wind speed or gust to be classified as severe weather in the USA is $26 \mathrm{~m} / \mathrm{s}$ (50 knots). This wind gust criteria has been used for public warnings in the USA since 1970 (Galway, 1989). However, the warnings are verified for any thunderstorm wind damage, even if a gust meeting the criteria is not recorded.

Hail is used as a warning criterion in 15 countries ( $58 \%$ of the 26 countries that issue severe thunderstorm warnings) (Table 1$)$. In 7 (27\%) of those 26 countries, warnings are issued for hail, regardless of size. A typical warning criterion is $2 \mathrm{~cm}$ (Table 1$)$, whereas the criterion in the USA is $1.9 \mathrm{~cm}(3 / 4 \mathrm{in}$.). (The $3 / 4$-inch criterion arose in the USA because it was "the smallest size of hailstones that could cause significant damage to an airplane flying at speeds between 200 and 300 mph" Galway, 1989; Lewis, 1996, p. 267).

The countries that do not use the expected severe weather as a warning criterion base their severe thunderstorm warning criteria on the number of cloud-to-ground lightning strikes, radar reflectivity factor of a certain magnitude, or forecast parameters (e.g., CAPE exceeding a certain value). Several countries issue severe thunderstorm warnings for thunderstorms with heavy precipitation ( 6 mentioned this, although not specifically asked in the questionnaire) or tornadoes ( 4 countries).

Of the 26 countries that issue severe thunderstorm warnings, 22 (85\%) base the warning on radar-detectable severe-storm features, although only 7 (27\%) look for a mesocyclone signature, which is one of the tools for the warning decision-making process in the USA (e.g., Hoium et al., 1997; Andra et al., 2002). Only 12 (46\%) use severe weather reports, which are mostly from observation stations. Twelve countries (46\%) use satellite imagery as the basis for severe thunderstorm warnings. Only one country, Bulgaria, relies solely on NWP model output in their warning decisionmaking process.

\section{Tornado warnings in Europe}

Only 8 (31\%) out of the 26 respondent European NHMSs that issue warnings issue tornado warnings (Fig. 2), and 7 have issued tornado warnings in the past. In Spain, a tornado warning is included in a severe thunderstorm warning, if tornadoes are expected. In the Netherlands, the warning is for waterspouts only, not for tornadoes over land. Some countries (3, or $12 \%$ mentioned this, although not specifically asked in the questionnaire) issue thunderstorm wind gust warnings, if tornadoes

Table 1

Severe thunderstorm warning criteria (minimum wind gust speed $(\mathrm{m} / \mathrm{s}$ ) or hail size $(\mathrm{cm}))$ if specified.

\begin{tabular}{|c|c|c|c|c|c|c|}
\hline Country & Gust speed (m/s) & & & Hail size $(\mathrm{cm})$ & & \\
\hline Austria & 17 & & & Any & & \\
\hline Bulgaria & 14 & 20 & 25 & Any & & \\
\hline Cyprus & 19 & 22 & 25 & - & Hailstorm & Severe hailstorm \\
\hline Czech Republic & 22 & & & 2 & & \\
\hline Estonia & 25 & & & No & & \\
\hline Finland & 15 & 20 & 30 & No & & \\
\hline Germany & 18 & 29 & & Any & 1,5 & \\
\hline Greece & $<21$ & 21 & 32 & Any & $1-2$ & $>2$ \\
\hline Hungary & 17 & 25 & Widespread 25 & Any & 2 & Widespread 2 \\
\hline Italy & 22 & & & - & & \\
\hline Latvia & 20 & 25 & 33 & - & & \\
\hline Lithuania & $15>1 / 3$ Lithuania & 28 & 33 & Any $>1 / 3$ Lithuania & 2 & \\
\hline Malta & 25 & & & 2 & & \\
\hline Netherlands & 28 & & & No & & \\
\hline Poland & 20 & & & - & & \\
\hline Portugal & 19 & 25 & 36 & No & & \\
\hline Romania & 15 & & & 2,5 & & \\
\hline Slovak Republic & 17 & 25 & 35 & - & & \\
\hline Slovenia & 20 & & & - & & \\
\hline Spain & 11 & 20 & & Any & 2 & 2 \\
\hline Switzerland & 21 & & & 2 & & \\
\hline Turkey & 16 & & & Any & & \\
\hline Ukraine & 25 & & & - & & \\
\hline
\end{tabular}

Some countries have more than one awareness level ( 2 or 3 ) for their severe thunderstorm warnings. "-" represents warnings issued for severe thunderstorms, but no hail-size threshold. "No" represents no warning for hail. "Any" represents warnings issued for any hail size. 


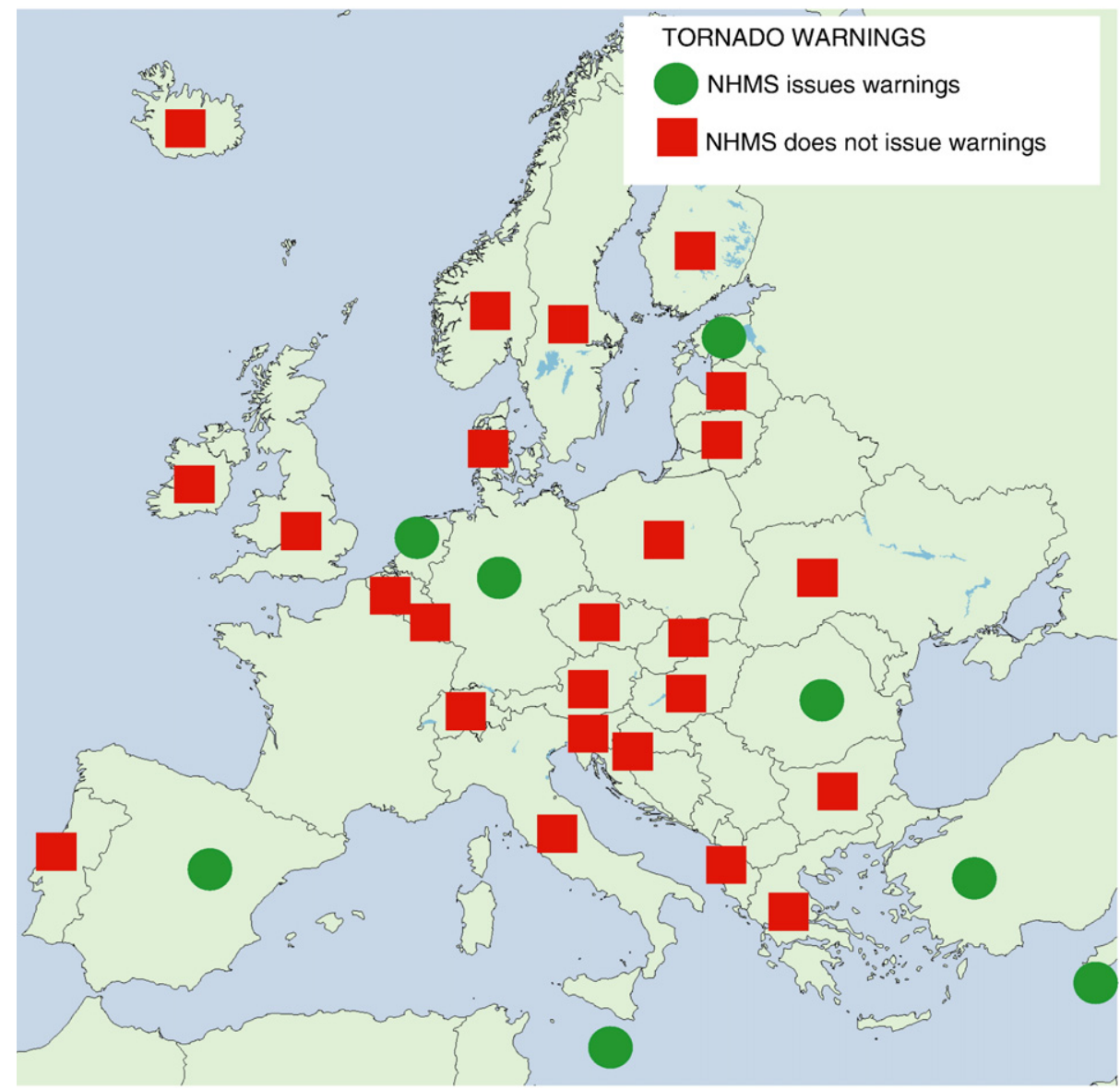

Fig. 2. Tornado warnings by European National Hydro-Meteorological Services (circles). The countries that don't issue tornado warnings are denoted by a square.

are expected. Two countries stated that, because tornadoes are such a rare phenomenon, they do not issue warnings for them. One country wondered if distinguishing between tornadoes and straight-line wind damages was worthwhile because the latter is believed to produce more fatalities.

In Germany, Netherlands, and Cyprus, tornado warnings are issued on the basis of observations of tornadoes already on the ground, whereas tornado warnings are issued based on the forecast in Malta, and on the basis of radar data and algorithms in Estonia, Romania and Turkey. Of the 7 European countries that have already issued tornado warnings, the lead-time is zero in the three countries where the warning is based on visual observation. When the warning is mainly based on radar data and algorithms, as in Estonia, Romania and Turkey, the lead-time is less than an hour, typically 20$30 \mathrm{~min}$. For comparison, the average lead-time for tornado watches in the USA is $2 \mathrm{~h}$ and $19 \mathrm{~min}$ (in 2006) and for tornado warnings in the USA is 14 min (in 2006-2007). Similarly to Finland's severe thunderstorm warning program where different time scales are treated in a similar manner (as discussed in Section 4), some countries do the same for tornadoes. For example, in Malta, where the tornado warning is issued purely on the basis of a forecast, the typical warning lead-time is $24 \mathrm{~h}$. At shorter time scales, however, nowcasting using radar and visual observations facilitates the warning decision-making process.
As far as we are aware, the first tornado warning in Europe was issued in the Netherlands in 1967. The warning was based purely on a forecast. After the damages and death toll of that tornado, the word tornado was not used again in public weather forecasts for fear of arousing a panic. A similar rationale has been previously used in the USA (Bradford, 1999; Doswell, 2007). At the time of writing of the present paper, the Netherlands issues warnings for waterspouts based on visual observations only, and the word tornado is still not used. The second European tornado warning was issued 10 years later when Cyprus issued their first tornado warning in 1977.

Five European countries issued their first tornado warning during 2003-2006: Estonia, Malta, Romania, Germany, and Turkey. For example, Romania issued their first tornado warning on 28 May 2005. Forecasters were alerted to the developing scenario by a convergence line in satellite imagery. Later, radar-data algorithms for mesocyclones and tornado detection were used as guidance. Because this warning was the first tornado warning issued in Romania, the mesoscale forecaster, who is responsible for warnings in the Center of Operational Forecasts at the National Meteorological Administration, and the synoptic forecaster, discussed with the deputy director and with a severe-weather expert before issuing the warning. The warning was issued for an area approximately $170 \mathrm{~km}^{2}$. Ten minutes after the tornado warning was issued, a local TV station reported a funnel cloud. 
Table 2

Example tornado warning statements in some European NHMSs and in United States of America.

\begin{tabular}{|c|c|}
\hline Cyprus & $\begin{array}{l}\text { A tornado was observed in LOCATION at TIME, moving } \\
\text { DIRECTION dissipating. }\end{array}$ \\
\hline Germany & $\begin{array}{l}\text { At TIME a tornado was observed at LOCATION. In the next } X \\
\text { minutes the thunderstorm with the risk of local tornados } \\
\text { moves in DIRECTION and can affect LOCATION. }\end{array}$ \\
\hline Malta & $\begin{array}{l}\text { Tornado watch from TIME to TIME: Good possibility of } \\
\text { tornadoes, heavy rain, flooding, large hail and damaging } \\
\text { winds. }\end{array}$ \\
\hline Netherlands & $\begin{array}{l}\text { On LOCATION waterspouts have been observed. In next } \\
\text { hours more spouts could develop. }\end{array}$ \\
\hline Turkey & $\begin{array}{l}\text { According to data received from Ankara radar and the } \\
\text { latest meteorological interpretation: It is estimated that } \\
\text { cloud masses near LOCATION will grow large and they } \\
\text { will cause severe weather damages as large hail, heavy } \\
\text { precipitation, strong wind, and risk of a tornado. }\end{array}$ \\
\hline \multirow{3}{*}{$\begin{array}{l}\text { United States } \\
\text { of America }\end{array}$} & Tornado warning for LOCATION \\
\hline & Until TIME \\
\hline & $\begin{array}{l}\text { At TIME law enforcement reported a tornado LOCATION } \\
\text { moving DIRECTION at SPEED. Some locations affected } \\
\text { LOCATION. }\end{array}$ \\
\hline
\end{tabular}

Later that summer, the first tornado warning in Germany was issued by Deutscher Wetterdienst (DWD) on 27 July 2005. Before the warning, a funnel cloud was observed at one of the weather stations. The forecaster could identify a relevant severe convective cell from radar and issued severe weather warnings for the relevant region, including notification that tornadoes were possible with these severe thunderstorms. In the warned area, at least one damaging tornado was observed. A year later, Turkey issued their first tornado warning with 30 min leadtime on 26 May 2006. The environment was noticed to be favorable for severe convective storms. A severe storm with elevated reflectivity core and overshooting top was identified from radar and satellite images, respectively. After the tornado, a bounded weak echo region and a mesocyclone were observed on radar. The warning was verified afterwards by calling the authorities in the expected damage area; tornado and hail damages were confirmed.

Table 2 gives some example statements of tornado warnings issued in several European countries and in the USA. (Additional examples of USA severe-weather dissemination products can be found in Moller (2001, Section 11.5).) Most of the European statements start with information about the location of the observed tornado or severe storm and the period of validity of the warning. The area affected or the direction of movement is mentioned only in a few tornado warning statements. Only one statement included information on the observation method. To reach the people at risk, three countries in Europe that issue tornado warnings transfer their warnings to civil protection authorities. Warn-

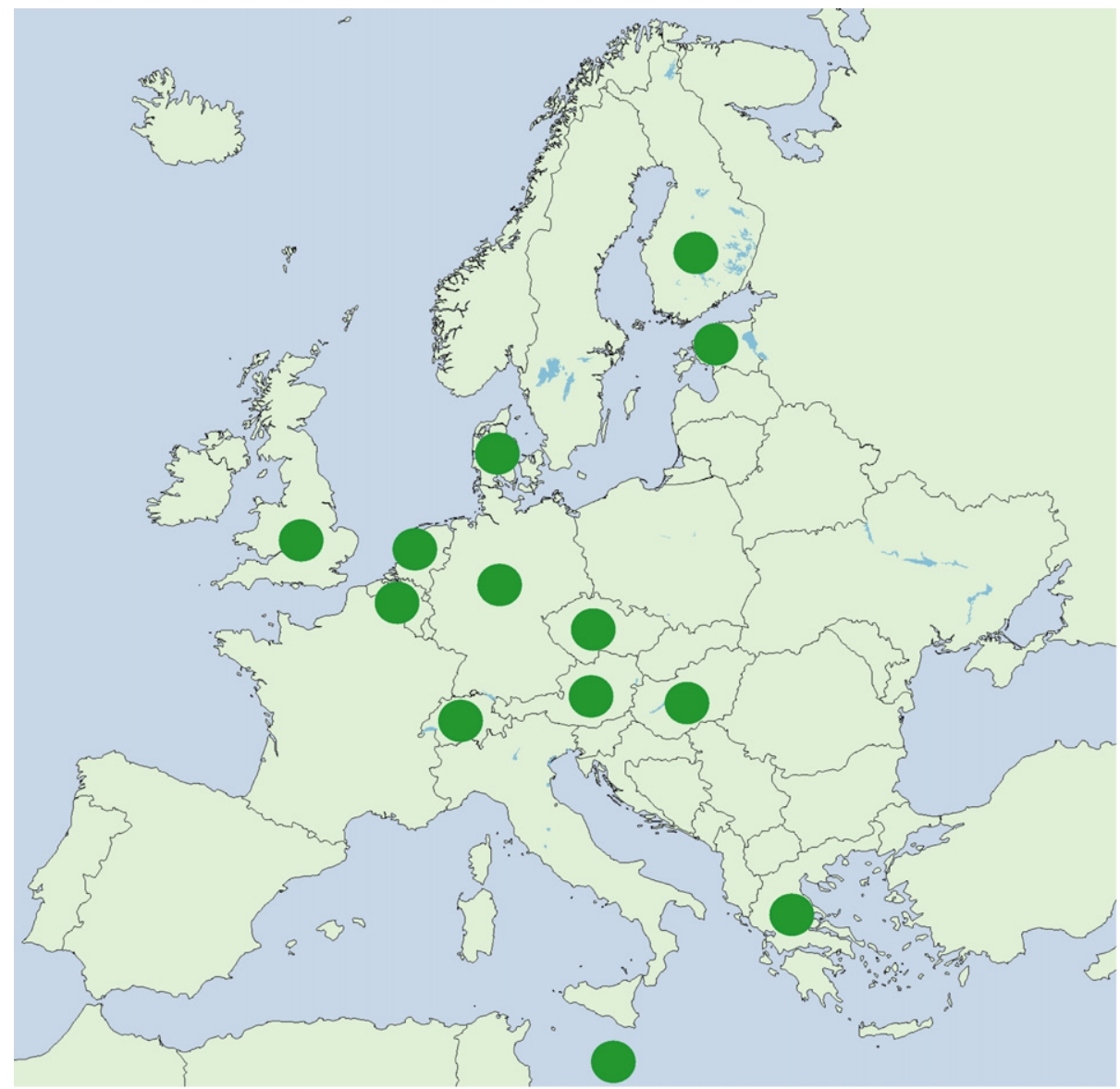

Fig. 3. Spotter networks in European countries. 
ings are also sent to the media and displayed on NHMS public Web pages (3 countries). In the Netherlands, the warning message is also sent to the people within the risk area by text message via mobile phone.

\section{Communication issues}

Recognizing and forecasting the threat of severe weather is only a component to a larger warning framework. An effective warning process also requires communication-confirmation of any severe weather occurrences from ground-truth observations (Section 6.1), distributing the message to the public and civil protection authorities (Section 6.2), and verifying the forecast (Section 6.3).

\subsection{Ground-truth observations}

At least 13 countries ( $46 \%$ of the 28 respondents to this question) have a spotter network (Fig. 3). Only 6 countries use the spotter reports operationally when issuing warnings. For example, the Hungarian Meteorological Service has an official contract with an amateur spotter group, from which the warning meteorologist receives the reports operationally. Another example is the DWD in Germany, which has close contact with the spotter group Skywarn. As the spotter sends the report by mobile phone, the warning meteorologists at DWD receive a voice mail within a few seconds. Some countries use spotter reports only to maintain the severe weather statistics. Finally, some NHMSs do not have any contact with existing spotter groups.

Ten countries ( $48 \%$ of respondents to this question) use severe weather reports collected from the general public in their warning decision-making process. Some (3 countries mentioned this although it was not specifically asked in the questionnaire) use online forms on their public Web page to collect severe weather reports, but they are often used for statistics and verification rather than for warning decision. The reports from the public may be received also by phone. Reports from the media are used in warning decision making by 7 countries (33\%). Reports from emergency authorities were used by 10 respondents (48\%) in their warning decisionmaking process. For example, the Finnish Meteorological Institute (FMI) receives weather-related emergency reports directly from the Emergency Response Centers, which receive emergency calls and coordinate rescue work. These emergency reports are transferred in real-time to the meteorological workstations at FMI. In Germany, close co-operation exists where the emergency authorities have a telephone hotline number to the DWD, as well as an online form to report severe weather. In at least two countries, the manual weather stations inform the warning forecasters on ongoing dangerous weather events and report the damage. Seven (33\%) of the 21 respondents did not use any of the abovementioned ground-truth observations, outside of their operational surface observing network, in their warning decisionmaking process.

\subsection{Distributing the message}

Almost all (22, or $85 \%$ ) of the 26 countries that issue severe thunderstorm warnings distribute their severe thunderstorm warnings to the general public by the NHMS Web page. Eighteen (70\%) NHMSs co-operate with the media in major severe thunderstorm events (to be discussed shortly); most typically, this means distributing warnings. In 6 countries (23\%), the dissemination of warnings to the general public is partly the responsibility of civil protection authorities. Text messages by mobile phone are used in severe thunderstorm warning dissemination in three countries (12\%).

The national broadcasting company is, in some countries, responsible for broadcasting the warnings at regular hours. Although co-operation with the media exists, 16 countries (62\% of those 26 that issue severe thunderstorm warnings) do not have extra means to distribute information on upcoming major events to the media, other than those warnings that are routinely distributed. Only 10 respondents (38\%) described such practices. In 6 countries (23\%), the warning forecasters may give radio or TV interviews/ outlooks before or during the event. News releases or special bulletins are issued before major events in two countries (8\%). The forecasters may also have direct phone contact to TV weather presenters, who may shift the emphasis of the broadcast to severe weather. Only two countries (8\%) mentioned governmental/local regulations that require severe weather warnings to be published immediately in the media.

An example of how dissemination of information in major events can be managed comes from Finland. Besides the routine warning distribution to media, in severe thunderstorm situations, the Finnish Broadcasting Company TV weather broadcasters are briefed over the telephone by FMI meteorologists. If the event is significant, a short outlook of the expected severe weather may be published on the FMI Web page. For major events, a public news release is issued, sometimes a day before the event. Media interviews are given, although they are more often requested during or after the event rather than before. In case of a weather disaster, FMI-formulated official emergency announcements will be published immediately on all radio and television stations, as prescribed by law.

Some co-operation with civil protection agencies occurs in almost all countries that issue severe thunderstorm warnings (25, or $96 \%$ ). In a major severe thunderstorm event, a few (7) countries distribute only the public warning message to emergency authorities, whereas at least 16 (62\%) have developed their co-operation further. Thirteen (50\%) of the institutes are in phone contact with civil protection authorities before and during major events; in six countries (23\%), a meteorologist may be a member of a crisis management group consisting of different authorities. Special outlooks on severe weather development are distributed to emergency authorities by several NHMSs.

An example of a well-organized co-operation between the NHMS and civil protection authorities is Portugal where the co-operation is organized by a daily severe-weather briefing. The video-conference is led by a Meteorological Institute shift forecaster, and the participants are the operational command chief and representatives from areas related to civil protection (e.g., firefighters, telecommunications). To maintain the routine, the video-conference is also organized on days when severe weather is not expected.

Another example is from Finland, where a designated severe weather forecaster at FMI is responsible for severe 
weather outlooks that may be disseminated to emergency authorities up to $48 \mathrm{~h}$ before a severe thunderstorm event (Punkka and Teittinen, 2007). The outlooks are updated more frequently as the event nears. The severe weather forecaster also supports the warning forecaster in decision making and gives briefings to forecasters, authorities and media. In major events, a public news release may be issued. Currently, the outlook is delivered to more than 150 different authorities in Finland.

The severe thunderstorm warning message includes instructions or guidance for the public to take cover or action in 5 surveyed countries. Another 3 NHMSs provide this guidance on a separate Web page. In 5 countries, the guidance is provided by civil protection. There are also other ways to stress the severity of the event. For example, in the Netherlands, possible consequences (e.g., uprooted trees) are mentioned in some of their warning messages.

\subsection{Verification of warnings}

Seventeen (77\%) of the 22 respondent countries that issue severe thunderstorm warnings verify them operationally; two countries (9\%) verify only after major events. Fifteen (79\%) of these 19 countries use surface weather observations in their verification procedure. Quite many countries use lightning or radar data in warning verification. Media reports are used by 6 countries, reports from spotters or public by 3 countries, and reports from emergency authorities by 3 countries. Ground-truth observations, not including those from the operational surface-observing network, are used only by a few countries. In fact, 8 (47\%) of the 17 countries that verify the severe thunderstorm warnings operationally do not use these ground-truth reports in their verification. Such a situation is possibly because of the lack of connections to spotter networks ( 10 countries, or $59 \%$ of the verifying countries have a spotter network), no connections with civil protection authorities, or lack of resources for collecting ground-truth observations. One country stated its future intention to use the European Severe Weather Database (http://essl.org/ESWD/) for verification.

\section{European challenges}

The results from our questionnaire have illuminated many aspects of the warning process within these 33 countries. Despite the variety in the operational warning systems in the different countries, several key challenges common to many, if not all, countries were apparent. We discuss these challenges in this section. Specifically, they are the lack of ground-truth observations (Section 7.1); forecast and nowcast methodologies, lead-time, and dissemination challenges (Section 7.2), international co-operation (Section 7.3), and the lack of tools (Section 7.4).

\subsection{The importance of ground-truth observations}

The first major shortcoming in severe thunderstorm warning processes in European countries is the lack of ground-truth reports, both in the warning decision-making process and in forecast verification. Radar data alone is not sufficient to issue warnings (e.g., Hoium et al., 1997; McCarthy,
2002). Surface weather observations may be used to collect reports, but, because severe weather typically occurs in localized areas, often in between official surface-observing stations or recording instrumentation, the ground-truth severe weather observations have to be collected by other means (e.g., eyewitness and damage reports). These reports may be obtained from emergency authorities, media, the public, or from the spotter network. The history of stormspotter networks is described in Doswell et al. (1999) and Moller (2001, 467-469), and specific examples of the importance of ground-truth observations for the 3 May 1999 tornado outbreak is described in McCarthy (2002). Still, in Europe, less than $20 \%$ of the 33 respondents use the spotter reports in the warning decision-making process.

Moreover, ground-truth reports are needed for forecast verification. If only operational surface weather observations are used in verification, as in the case of 8 of the respondent countries who verify their severe storm warnings operationally (Section 6.3), too many events may be missed and false alarm rates may be high. Missing part of the true number of events in verification will evidently lead to biased understanding of the full range of events and to worse forecasts and warnings. Collecting the ground-truth reports requires some efforts from each NHMS. Moreover, even in an area of heavy concentration of meteorologists (Norman, Oklahoma, USA), verification of tornado tracks and finding resources for adequate post-storm verification can be challenging (Speheger et al., 2002).

\subsection{Methods, lead-time and dissemination of warnings}

The available forecasting and nowcasting tools and methods affect the warning lead-time and also its confidence. If the warning is issued based on observations of severe weather, forecaster confidence is high, but lead-time is close to zero, as it is in the three countries that have issued their tornado warnings only on the basis of observations (Cyprus, Germany, and the Netherlands). These warnings, however, may provide tens of minutes lead-time on any successive severe weather produced by the same storm.

Radar data has the potential to provide more lead-time with accurate information on the potential location of severe weather, but, when used alone without the ground-truth observations, the credibility is lower. Since radar measurements are above ground, even a radar-observed tornado vortex signature does not always imply a confirmed tornado on the ground. When radar observations are used together with a forecast, the warning lead-time can be increased further. For example, if the environment is favorable for tornadoes and if a severe thunderstorm is observed by radar, an area of higher tornado potential may be defined along the predicted storm path. Radar, or even satellite, observations of onset of deep moist convection in a tornado-prone environment can be used for an alert over a larger area. However, in such warnings, the timing, location or even existence of tornadoes is not confirmed.

Based on this questionnaire, a mesocyclone signature is used in severe thunderstorm warning decision-making process only in a few European countries. Although questions on radar coverage, scanning strategies or forecaster products were not included in this questionnaire, the results suggest 
that Doppler radar velocity data are not operationally used in most of the European countries that issue severe thunderstorm warnings. Yet, many countries use satellite images as critical information in the warning decision-making process, which is likely influenced by recent EUMETSAT efforts to improve thunderstorm nowcasting products.

If the conditions for locally favorable severe storm environments and the climatological limitations are known, the severe thunderstorm risk may be forecasted based on anticipated environmental characteristics and conceptual models. With NWP models, the risk may be forecasted even several days in advance, with increasing accuracy as the lead-time decreases and the number of observations to support forecasting increases. If these forecasts are used for warnings, the warning areas are inevitably large and the probability at any one forecast point is relatively low. This is likely the case in several countries in Europe, who issue their warnings as much as $24 \mathrm{~h}$ before the event, akin to the outlooks issued by the SPC in the USA. In countries where the typical lead-time is minutes or a few hours, detecting severe storms play a major role in the warning decision-making process, and the warning process is more akin to the USA severe thunderstorm warnings.

The different European countries were asked about what techniques they used to issue tornado warnings. In the USA, Andra et al. (2002) stated that, during the 3 May 1999 tornado outbreak, forecasters at the Norman NWSFO used a methodology to issue warnings that included "1) scientifically based conceptual models of storm types and their environments, 2) Doppler radar data, 3) ground-truth observations, 4) technology, 5) strategy, and 6) human expertise." Using this classification scheme, we found that none of the European countries mentioned conceptual models, three out of 7 countries used Doppler radar data and four used ground truth observations. Andra et al. (2002) found that the median leadtime for the computer algorithm for detecting tornadoes was $2 \mathrm{~min}$, but $29 \mathrm{~min}$ for the human forecasters. Thus, experienced forecasters were able to improve upon automated guidance.

Since the tornado warning lead-time is often only tens of minutes or the vortex is already on ground, special attention should be paid to give the warning forecaster proper tools and prewritten parts of the warning statements that enable fast modifications of the warning statement and its distribution to relevant audiences. For the person in a risk area, the most crucial information in a tornado warning statement is the area affected along the storm path and the time frame of the warning. If the tornado is already observed, it should be mentioned to stress the imminent danger. If a warning leadtime is only a few tens of minutes, there are extra challenges in distributing the warning message to end users, reaching the persons at risk.

\subsection{International co-operation}

The third main challenge in Europe is in exchanging both warning information and severe weather observation reports. Severe weather does not follow country borders. Typically a severe weather event affects several European countries simultaneously or over several days, making the exchange of information between countries the major challenge in Europe. Because every country is responsible for warnings in their area and has different warning criteria, countries do not necessarily have to agree when issuing warnings. For a good warning decision, one would, however, very often need to know the severe weather reports and information on warnings on the other side of country borders.

Yet, most of the respondents have some bilateral cooperation with neighbouring countries in severe storm events, typically done by exchanging information between two countries. However, 10 countries that issue severe thunderstorm warnings do not have any bilateral co-operations during major events. The lack of co-operation is apparent in southeastern Europe, in contrast to central and northeastern Europe where interaction is common. The most common bilateral form of co-operation in a severe storm event is to exchange warnings (16 countries, or $62 \%$ of countries that issue warnings). One third ( 9 countries) also exchange severe weather reports with their neighbours. Only bilateral exchange of information does not, however, mean that the forecasters necessarily have a big picture of severe weather occurring outside of all country borders, which could be needed in severe weather outbreak situations. Only in four countries do the forecasters have phone conferences with a neighbouring country during severe weather. These forecaster discussions during, and especially before, the severe weather episode, could be a significant help in the preparedness in the forecasting offices or even in the warning decision-making process.

The exchange of warning information in Europe has become easier since Meteoalarm became operational in March 2007. On the Meteoalarm Web page (www.meteoalarm.eu), the European weather warnings from EUMETNET countries are displayed in one figure. The European Severe Weather Database (ESWD, http://essl.org/ESWD/ ) is a webbased interface where the public and NHMSs can submit and retrieve severe weather reports. If fully operational in real time, ESWD has potential to become a major tool for severe thunderstorm nowcasting and warning operations when severe weather advances over Europe. Even still, not all European NHMSs participate in Meteoalarm or ESWD.

\subsection{The challenges the NHMSs pointed out}

The fourth major shortcoming in Europe is both lack of forecasting and nowcasting tools and knowledge among forecasters. When the respondents were asked what are the biggest challenges in severe thunderstorm forecasting, 19 European NHMSs stated the need of more forecasting tools. In addition, more than half of the respondents admitted their lack of forecasting knowledge. Similarly, in issuing severe thunderstorm warnings, both nowcasting tools and knowledge was not adequate in 17 European NHMSs. Lack of local research to support forecasting was recognized as limiting the skills in 13 countries; for example, complex terrain, such as mountains, provide challenges in forecasting events. Also, nine countries suggested more local research to support warning decisions was needed.

One solution to this challenge is collaboration between research meteorologists and operational forecasters (e.g., Kain et al., 2003a,b). Such interaction can be an effective way to improve forecasting, as well as identify new research topics. Experience at the SPC and the USA government research laboratory NOAA National Severe Storms Laboratory, now collocated in the National Weather Center in Norman, 
Oklahoma, USA, shows the power of such collaborations when focused on operationally relevant forecast problems (e.g., Kain et al., 2003a,b).

The lack of forecaster experience with severe weather ( 2 countries) and the availability of forecaster training ( 3 countries) are problems that some countries identified. Some NHMSs view the end users' understanding of the phenomena (3 countries) and problems to deliver the warning to the risk area ( 2 countries) as some of the major challenges. Lack of full radar coverage, as is the case in four European countries, was recognized as a limiting factor to both severe thunderstorm and tornado warnings. Two countries also suggested that increasing the number of forecasters would help attain better severe storm forecasting and warnings.

According to NHMSs, the most common, 59\% (10) of respondents, challenge in issuing tornado warnings in Europe is the lack of adequate nowcasting tools. Half of the respondents (9) identified the need for local research and knowledge for nowcasting. As tornadoes are relatively rare events, the lack of experience that an individual forecaster has on tornado nowcasting was viewed also as limiting factor by three countries, as also noted by Doswell (2005). Surprisingly, only three countries (18\%) pointed out the lack of enough spotter reports, as a challenge in issuing tornado warnings.

\section{Conclusion}

In regions where the threat of severe weather is low, producing effective forecasts and responses can be challenging (e.g., Doswell, 2001). Without a large number of events to train upon, forecasters are often poorly prepared to recognize the threat of severe weather (Doswell, 2005, p. 85). Furthermore, the government or weather service may not even formally recognize the threat of severe weather, either internally or to the public. Without the recognition of the possibility of such events, databases for the collection of such events and their verification are unlikely to be created. Finally, the low threat means that residents are typically not well prepared or know what to do if an actual event were to occur. Given that the public wants to get consistent warning information from multiple reliable sources (Mileti and Sorensen, 1990), a single message reaching the public within such a system may not initiate a response. These are the types of challenges that face European countries, especially those with a lower threat of severe weather.

Relative to the threat that severe weather poses to European societies, the efforts in collecting reports, maintaining records, and conducting research that supports both forecasting and warning operations have been rather sparse in European countries up until recently. Before a NHMS may maintain successful forecasting and warning operations, some fundamental work in these areas has to be done. For example, a fast solution to adapt forecast-parameter-based criteria or conceptual models used in another country may seem feasible, but without a deeper understanding of the local severe storm environments, the skill of the forecasts may be limited. Consequently, cooperative research efforts and exchange of knowledge, not only between European countries, but also between Europe and the USA would be beneficial to developing the forecasting and warning operations in the European countries.
Our study has compiled the results of a questionnaire distributed to 39 European countries (33, or 85\%, responded), yielding the most detailed picture to date of severe weather warning operations across Europe. The results in the paper show the variety of forecasting, nowcasting, warning, and communication systems that have evolved in the different respondent countries. Underlying this study, we find that collaborative training efforts are needed in Europe to exchange information on forecasting and nowcasting tools to provide the forecasters adequate knowledge to improve their warning operations. The results and practices presented can be used by decision makers when developing severe storm forecasting or warning programmes in individual NHMSs. We also hope that the ideas shared within the present paper will lead to discussions within individual countries, as well as among the various countries, for improving warning operations and communication. These ideas should challenge the scientific community to work with the operational forecasting community to identify weaknesses in the understanding of severe weather and to develop collaborative research programmes that support their forecasting and nowcasting operations.

\section{Acknowledgements}

We would like to thank all representatives of European NHMSs and NOAA in the USA who have provided information on their national warning programs: Tanja Porja, Institute of Hydrometeorology, Albania; Thomas Krennert and Michael Staudinger, Central Institute for Meteorology (ZAMG), Austria; Ludo Van der Auwera and Karim Hamid, Royal Meteorological Institute of Belgium, Belgium; Gergana Kozinarova, National Institute of Meteorology and Hydrology, Bulgaria; Dunja Drvar, Meteorological and Hydrological Institute of Croatia, Croatia; Keti Savvidou, Meteorological Service, Cyprus; Milan Salek, Czech Hydrometeorological Institute, Czech Republic; Søren Olufsen, Danish Meteorological Institute (DMI), Denmark; Merike Merilain, Estonian Meteorological and Hydrological Institute (EMHI), Estonia; Thomas Schumann and Andreas Friedrich, Deutcher Wetterdienst (DWD), Germany; Chalkis Vasileios, Hellenic National Meteorological Service, Greece; Kornél Kolláth, (OMSZ), Hungary; Sigrún Karlsdóttir, Icelandic Meteorological Office (IMO), Iceland; Joanna Donnelly and Michael Walsh, The Irish Meteorological Service, Ireland; Fulvio Stel, OSMER-ARPA and Giuseppe Frustaci, Italian Meteorological Service (CNMCA), Italy; Laura Karklina, Latvian Environment, Geology and Meteorology Agency, Latvia; Izolda Marcinoniene, Lithuanian Hydrometeorological Service, Lithuania; Jacques Zimmer, Service Meteorologique de l'Aeroport de Luxenburg, Luxembourg; Mark Vella Gera, Malta Weather Service, Malta; Frank Kroonenberg and Jacob Kuiper, (KNMI), Netherlands Norvald Bjergene, Met.no, Norway; Monika Pajek, Iwona Lelatko and Monika Kaseja, Institute of Meteorology and Water Management, Poland; Teresa Abrantes, Meteorological Institute (IM), Portugal; Aurora Stan-Sion, Carolina Oprea and Bogdan Antonescu, National Meteorological Administration, Romania; Nikolay Veltishchev, Hydrometeorological Reseach Centre of Russia, Russia; Jozef Csaplar, Hydrometorological Institute, Slovak Republic; Janez Markošek, Environmental Agency of the Republic of Slovenia, Slovenia; Ana Casals and Fermin Elizaga, Instituto Nacional de Meteorologia, Spain; Begt Lindström, Swedish Meteorological and Hydrological Institute 
(SMHI), Sweden; Paolo Ambrosetti, MeteoSwiss, Switzerland; Salman Gayretli and Fatih Berber, Turkish State Meteorological Service, Turkey; Vladimir Bakhanov and Ludmila Savchenko, Hydrometcenter of Ukraine, Ukraine; Nick Grahame and Bob Turner, UK Met Office, United Kingdom; and Peter Banacos and John Ferree, National Weather Service, and Gregory Carbin, Andy Dean, Roger Edwards, and Joseph Schaefer, Storm Prediction Center, USA.

\section{Appendix A}

Questions asked in the questionnaire and number of respondents to each question

Question
Severe thunderstorm forecasting
Does your Institute issue severe thunderstorm
(with damaging wind gusts or large hail or tornado)
forecasts hours before the storms have developed
(not a warning after the storms have already developed)?
If yes, what is the forecast lead time (compared to the first
severe weather report, for example 6 h, 12 h, 24 h)?
If yes, do you use these forecasts to issue early
warnings or watches?
What are the biggest challenges in forecasting severe
thunderstorms in your country? (For example, do you
need more forecasting tools, forecasting knowledge,
research in your country, or other? Please specify.)

Number of respondents

Severe thunderstorm warnings

Does your Institute issue severe thunderstorm

warnings when thunderstorms are expected to produce

- Damaging wind gusts?

- Large hail?

If yes, what criteria you use? (If you use several awareness levels/criteria, please specify.)

-Damaging wind gusts (gust speed)

-Large hail (hail size)

If yes, what is the typical approximate warning lead time (compared to the first severe weather report)?

If yes, on what information do you base the warning (severe weather report, mesocyclone signature on radar, other radar severe storm features, forecast, or other)? Please specify.

What are the biggest challenges in issuing severe thunderstorm warnings in your country? (For example, do you need more nowcasting tools, nowcasting knowledge, research in your country, or other. Please specify.)

Tornado warnings (tornadoes over both land and water)

Does your Institute issue tornado warnings?

If yes, when was the first tornado warning issued?

Please describe the case.

If yes, what is the typical approximate warning lead time (compared to the first tornado report)?

If yes, on what information have you based the warning (tornado observation, tornado vortex signature on radar, other radar storm features, forecast, or other)? Please specify.

What are the biggest challenges in issuing tornado warnings in your country? (For example, do you need more nowcasting tools, nowcasting knowledge, research in your area, or other?) Please specify.

Severe thunderstorm warning process

Does your country have a spotter network (organized group of people who report severe thunderstorm visual observations or damage)?
Appendix A (continued)

Question

Number of

respondents

Severe thunderstorm warning process

What severe weather observations does your Institute

use operationally when issuing severe thunderstorm

warnings?

- Reports from the public

- Spotter reports

- Media

- Reports from emergency authorities

- Other

- None

What types of interaction does your Institute have with the emergency authorities before and during a major severe thunderstorm event (conferences, products)?

How does the media receive information about forecasted severe weather before a major severe thunderstorm event (products)?

What kind of specific interaction does your Institute have with neighbouring countries before, during or after a major severe thunderstorm event? If interactions exist, which country or countries?

-Exchange of severe weather reports

- Exchange of severe thunderstorm warnings

- Forecaster conferences

- Other

- None

How do you distribute the severe thunderstorm warnings to the general public?

Do you verify your severe thunderstorm warnings?

If you verify warnings, what observations do you use in your verification procedure?

Does the severe thunderstorm warning message include instructions or guidance for the public to take cover or action? If so, please provide a sample message.

Additional questions for the countries that issue tornado warnings

Can you please give an example of your tornado warning statement?

What means you have to distribute the tornado warning to the persons at risk area?

\section{References}

Andra, D.L., Quoetone, E.M., Bunting, W.F., 2002. Warning decision making: the relative roles of conceptual models, technology, strategy, and forecaster expertise on 3 May 1999. Wea. Forecasting 17, 559-566.

Bradford, M., 1999. Historical roots of modern tornado forecasts and warnings. Wea. Forecasting 14, 484-491.

Brooks, H.E., Doswell, C.A., 2001. Normalized damage from major tornadoes in the United States: 1890-1999. Wea. Forecasting 16, 168-176.

Corfidi, S.F., 1999. The birth and early years of the Storm Prediction Center. Wea. Forecasting 14, 507-525.

Doswell, C.A., 2001. Severe convective storms-an overview. Severe Convective Storms, Meteor. Monogr. No. 50. In: Doswell, C.A. (Ed.), Amer. Meteor. Soc. pp. 1-26.

Doswell, C.A., 2003. Societal impacts of severe thunderstorms and tornadoes: lessons learned and implications for Europe. Atmos. Res. 67-68, 135-152.

Doswell, C.A., 2005. Progress toward developing a practical societal response to severe convection (2005 EGU Sergei Soloviev Medal Lecture). Nat. Hazards Earth Syst. Sci. 5, 1-12.

Doswell, C.A., 2007. Historical overview of severe convective storms research. Electronic J. Severe Storms Meteor. 2 (1), 1-25

Doswell, C.A., Moller, A.R., Brooks, H.E., 1999. Storm spotting and public awareness since the first tornado forecasts of 1948. Wea. Forecasting 14, 544-557.

Edwards, R., Corfidi, S.F., Thompson, R.L., Evans, J.S., Craven, J.P., Racy, J.P., McCarthy, D.W., Vescio, M.D., 2002. Storm Prediction Center forecasting issues related to the 3 May 1999 tornado outbreak. Wea. Forecasting 17, 544-558.

Galway, J.G., 1989. The evolution of severe thunderstorm criteria within the Weather Service. Wea. Forecasting 4, 585-592. 
Hoium, D.K., Riordan, A.J., Monahan, J., Keeter, K.K., 1997. Severe thunderstorm and tornado warnings at Raleigh, North Carolina. Bull. Amer Meteor. Soc. 78, 2559-2575

Johns, R.H., Doswell, C.A., 1992. Severe local storms forecasting. Wea. Forecasting 7, 588-612.

Kain, J.S., Janish, P.R., Weiss, S.J., Baldwin, M.E., Schneider, R.S., Brooks, H.E., 2003a. Collaboration between forecasters and research scientists at the NSSL and SPC: the Spring Program. Bull. Amer. Meteor. Soc. 84, 1797-1806.

Kain, J.S., Baldwin, M.E., Janish, P.R., Weiss, S.J., Kay, M.P., Carbin, G.W., 2003b. Subjective verification of numerical models as a component of a broader interaction between research and operations. Wea. Forecasting 18, 847-860.

Lewis, J.M., 1996. Joseph G. Galway. Wea. Forecasting 11, 263-268.

McCarthy, D.H., 2002. The role of ground-truth reports in the warning decision-making process during the 3 May 1999 Oklahoma tornado outbreak. Wea. Forecasting 17, 647-649.

McNulty, R.P., 1995. Severe and convective weather: a central region forecasting challenge. Wea. Forecasting 10, 187-202.
Mileti, D.S., Sorenson, J.H., 1990. Communication of emergency public warnings: a social science perspective and state-of-the-art assessment. Oak Ridge National Laboratory Rep. ORNL-6609, Oak Ridge, TN, p. 200.

Moller, A.R., 2001. Severe local storms forecasting. Severe Convective Storms, Meteor. Monogr. No. 50. In: Doswell, C.A. (Ed.), Amer. Meteor. Soc., pp. 433-480.

Ostby, F.P., 1992. Operations of the National Severe Storms Forecast Center. Wea. Forecasting 7, 546-563.

Ostby, F.P., 1999. Improved accuracy in severe storm forecasting by the Severe Local Storms Unit during the last 25 years: then versus now. Wea. Forecasting 14, 526-543.

Punkka, A.-J., Teittinen, J. 2007. The Severe Weather Forecasting Program in Finland. Preprints, 4th European Conference on Severe Storms, Trieste, CD-ROM.

Speheger, D.A., Doswell, C.A., Stumpf, G.J., 2002. The tornadoes of 3 May 1999: event verification in central Oklahoma and related issues. Wea. Forecasting 17, 362-381. 